\title{
Imaging of Nasopharyngeal Carcinoma
}

\author{
Michael Chan ${ }^{1}$, Eric Bartlett ${ }^{2}$, Arjun Sahgal ${ }^{3}$, \\ Stephen Chan ${ }^{4}$ and Eugene $\mathrm{Yu}^{5}$ \\ ${ }^{1}$ Faculty of Medicine, University of Toronto \\ ${ }^{2}$ Department of Medical Imaging and Otolaryngology-Head and Neck Surgery, \\ University of Toronto \\ ${ }^{3}$ Department of Radiation Oncology, University of Toronto \\ ${ }^{4}$ Division of Life Sciences, University of Western Ontario \\ ${ }^{5}$ Department of Medical Imaging and Otolaryngology-Head and Neck Surgery, \\ University of Toronto \\ Canada
}

\section{Introduction}

\subsection{Imaging of nasopharyngeal carcinoma}

Nasopharyngeal carcinoma (NPC) is the most common neoplasm to affect the nasopharynx (NP). Arising from the epithelial lining of the nasopharyngeal mucosa, NPC is distinct from squamous cell carcinoma affecting other sites of the pharyngeal space. NPC typically originates in the lateral wall of the nasopharynx and is noted as a locally aggressive neoplasm with a high incidence of metastases to cervical lymph nodes. The primary tumour can extend within the nasopharynx and/or to the base of the skull, palate, nasal cavity or oropharynx. Distant metastases can arise in bone, lung, mediastinum, and, more rarely, the liver (Brennan, 2006).

The etiology of NPC is multifactorial and involves many environmental and genetic risk factors (Henderson et al., 1976). In particular, diets high in salt-preserved foods - such as salted fish, meat, eggs, fruits and vegetables in the Southern Asian diet - have been identified as possible causative factors acting through the carcinogen, $\mathrm{N}$ nitrosodimethylamine ( $\mathrm{Yu}$ et al., 1988). In contrast, frequent consumption of fresh fruits and/or vegetables - especially during childhood - is associated with a lower risk of NPC. In addition, studies have indicated a causal role for the Epstein-Barr virus (EBV) in the development of NPC (Chang \& Adami, 2006). EBV is a DNA virus responsible for infectious mononucleosis, post-transplantation lymphoproliferative disease, and Burkitt's lymphoma. Elevated IgG and IgA antibody titres against viral capsid antigen, early antigen, and latent viral nuclear antigens have been noted in NPC patients. Furthermore, these antibodies have been shown to precede tumour development by several years. EBV DNA, RNA, and gene products have also been detected in tumour cells (Chang \& Adami, 2006). EBV serology is currently used as a screening tool for high-risk populations in southern China (Glastonbury, 2007). Certain genetic haplotypes - HLA A2, Bsn 2, B46, and B58 - are also associated with 
increased risk (Ren \& Chan, 1996). Other exposures implicated in NPC include cigarette smoking, other smoke, and occupational exposures including wood dust and industrial heat (Yu et al., 2010).

\section{Epidemiology of NPC}

NPC is a rare malignancy that exhibits a distinct ethnic and geographic variation (Chang \& Adami, 2006). While in most regions of the world, age standardized incidence rates for both males and females are < 1 per 100,000 person-years (Chang \& Adami, 2006; Chong, 2006)), higher rates are observed in a few well-defined populations. Studies have demonstrated intermediate incidence rates in several indigenous populations in Southeast Asia, the Arctic, and the Middle East/North Africa (ranging from 0.5 to 31.5 per 100,000 person-years in males and 0.1 to 11.8 person-years in females) (Chang \& Adami, 2006; Parkin et al., 2002), and endemic rates in the natives of southern China reaching 20-30 per 100,000 person-years and 15-20 per 100,000 person-years amongst males and females, respectively, in the province of Guangdong (Ho, 1978; Yoshizaki et al., 2011). In addition, within geographic regions, a distinct ethnic variation also exists. For example, in the US, rates are highest amongst Chinese Americans, followed by Filipino Americans, Japanese Americans, Blacks, Hispanics, and finally Caucasians (Burt et al., 1992).

Globally, there are more than 80,000 incident cases and 50,000 deaths annually due to NPC (Parkin et al., 2005). NPC shows a male predilection of 2-3:1 (Parkin et al., 2002). In low risk populations, incidence increases with age, while in high risk populations, incidence peaks in the $6^{\text {th }}$ decade of life and declines thereafter. NPC is rare in pediatric populations. Thus, the highest incidence rates are observed in middle-aged men (Chang \& Adami, 2006).

\section{Histopathology of NPC}

Three histologic subtypes are recognized by the World Health Organization (WHO) classification system:

- $\quad$ Type 1 - squamous cell carcinoma; typically found in older adult populations

- $\quad$ Type 1 is further subdivided into poorly, moderately, and well-differentiated

- $\quad$ Type 2 - non-keratinizing carcinoma

- $\quad$ Type 3 - undifferentiated or poorly differentiated carcinoma, including lymphoepithelioma and anaplastic variants; comprises most cases of childhood and adolescent NPC

In contrast to Type 1, Type 2 and 3 are associated with elevated EBV titres. In addition, Type 2 and 3 may also be accompanied by lymphoepithelioma, which is an inflammatory infiltrate of lymphocytes, plasma cells, and eosinophils. Histopathologic typing has prognostic significance, as Type 2 and Type 3 exhibit a more favourable prognosis and greater radiosensitivity than Type 1 . Risk factors for Type 1 include cigarette smoke and ethanol consumption, whereas Type 2 and 3 are the endemic forms (Brennan, 2006).

In NPC, two histological patterns may be recognized: (1) the Regaud type which is a welldefined collection of epithelial cells surrounded by lymphocytes and connective tissue, and (2) the Schmincke type, which appears as diffuse tumours intermingled with inflammatory cells (Brennan, 2006). 


\section{Presentation of NPC}

While some patients are asymptomatic, $50 \%$ to $70 \%$ of patients initially present with cervical lymphadenopathy in the form of a neck mass and are diagnosed by lymph node biopsy (Glastonbury, 2007). Symptoms at presentation may include trismus, pain, otitis media due to Eustachian tube dysfunction, nasal regurgitation due to paresis of the soft palate, and hearing loss. Depending on the degree of local infiltration, patients may also suffer from cranial nerve dysfunction and headache. Cranial nerve neuropathies (most often CN5 and CN6) are an indication of skull base infiltration. Larger growths may also produce nasal obstruction or bleeding and a "nasal twang". Metastatic spread may result in bone pain or organ dysfunction. Rarely, a paraneoplastic syndrome of osteoarthropathy may occur with widespread disease.

\section{Role of imaging in the management of NPC}

All stages of NPC patient management, from diagnosis and staging to treatment and followup, involve imaging. On presentation, a full diagnostic work-up for NPC involves a physical examination (including neurological examination of the cranial nerves), laboratory testing (including a complete blood count, liver function tests, and alkaline phosphate levels), an endoscopic-guided biopsy, as well as imaging studies. Since $6 \%$ of NPC is submucosal and cannot been seen on endoscopy (King et al., 2006), cross-sectional imaging studies, such as magnetic resonance imaging (MRI) or computed tomography (CT), are required to help confirm the diagnosis, as well as accurately demarcate the exact limits of pharyngeal wall involvement and tumour invasion into surrounding structures. Currently, MRI and CT are not routinely used for screening purposes; however, the radiologist should consider NPC whenever head and neck imaging is obtained, especially in high-risk patients - such as those of Asian descent - being evaluated for otitis media or with incidental findings of middle ear opacification.

Early findings of NPC on imaging include asymmetry of the nasopharynx and an obstructed Eustachian tube (ET) (Figure 1) (Glastonbury, 2007). Most NPC masses originate in the fossa of Rosenmuller, otherwise known as the lateral pharyngeal recess. Furthermore, involvement of the lateral pharyngeal recess may cause dysfunction of the ET - either directly or indirectly by infiltrating the surrounding musculature - leading to stasis of middle ear secretions and unilateral hearing loss (Figure 2). In cases of head and neck imaging for neck masses of "unknown primary," careful attention should be paid to the possibility of NPC since cervical lymphadenopathy is the most common presentation.

Like other neoplasms, a mainstay in NPC treatment is staging. Staging contributes information regarding prognosis and helps guide treatment planning, facilitate stratification of treatment, and coordinate clinical studies (Mao et al., 2009; Yu et al., 2010). While in the past, CT was preferred, MRI is currently the imaging modality of choice for NPC staging using the American Joint Committee on Cancer (AJCC) tumour, node, metastasis (TNM) staging system (King et al., 1999; Liang, 2009; $\mathrm{Ng}$ et al., 1997). CT still has a role in the assessment of bony skull base involvement (Olmi, 1995), but MRI is considered superior to CT for assessing primary tumour invasion into surrounding soft tissue and bony structures, pharyngobasilar fascia invasion, invasion into the sinus of Morgagni, skull base invasion, as well as cavernous sinus extension and perineural disease (Liao et al., 2008; Sakata, 1999). 


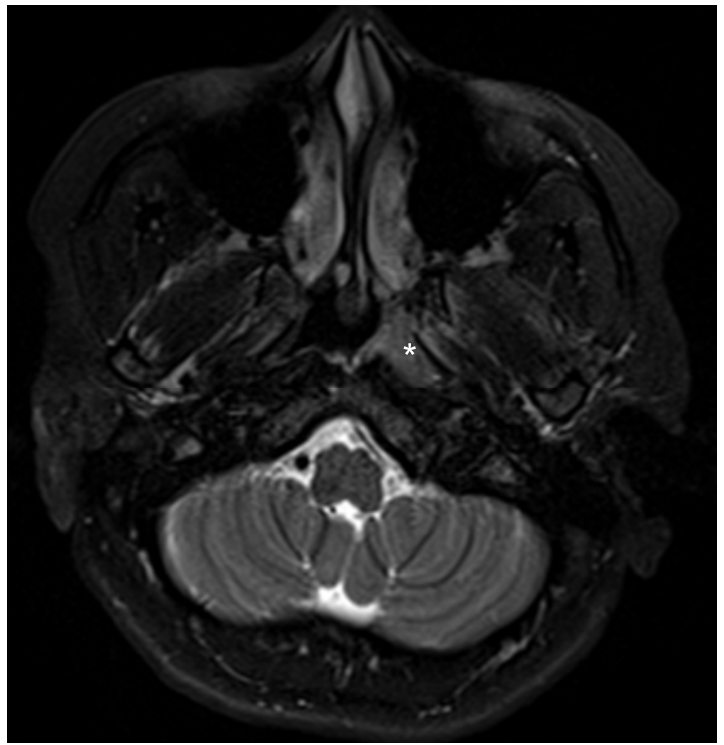

Fig. 1. Axial T2 weighted image shows a mass filling the left fossa of Rosenmuller $\left(^{*}\right)$.

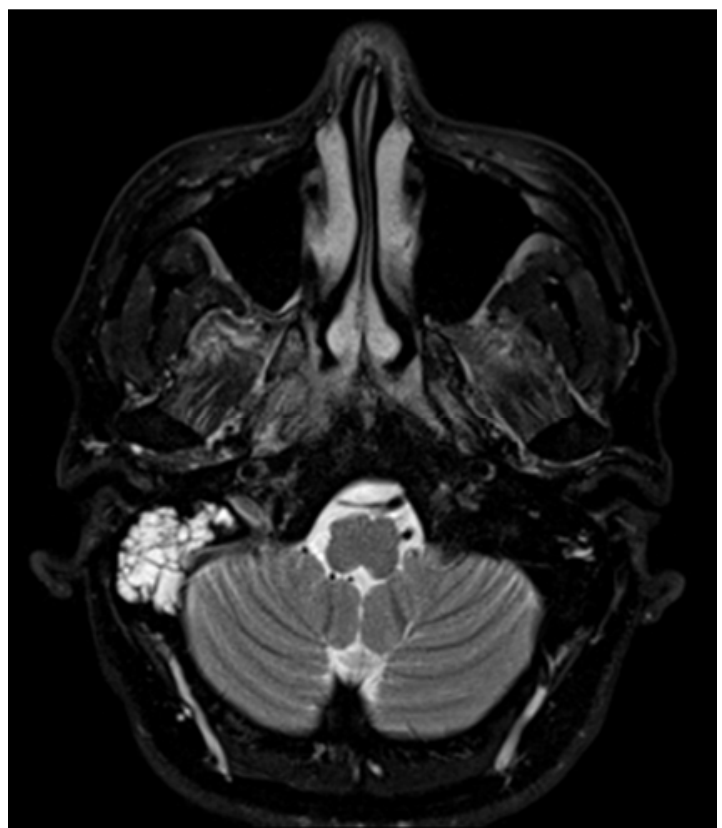

Fig. 2. Axial T2 weighted image shows a right sided NPC that is resulting in right Eustachian tube dysfunction and fluid build up in the right mastoid. 
MRI is also more reliable for differentiating between the primary tumor and retropharyngeal adenopathy (Chang, 2005; Chong, 1996; Chung, 2004; King, 2000). For patients with clinical or biochemical evidence of advanced disease, additional investigations - including bone scintigraphy, chest x-ray, CT of thorax, abdomen, and pelvis, and/or fluorodeoxyglucose (FDG)-positron emission tomography (PET)-CT imaging - may be indicated (Caglar, 2003; Chen et al., 2006; Chiesa \& De Paoli, 2001; Chua et al., 2009; Comoretto et al., 2008; Lee, 1992).

The mainstay of treatment in NPC is radiation therapy (RT) with the addition of concurrent and/or adjuvant chemotherapy reserved for higher stages of disease. Surgical salvage (nasopharyngectomy) has also been used in cases of recurrent disease (Yu et al., 2010). The goal of treatment is to be curative. To be effective, RT must target the primary lesion as well as any associated neck adenopathy. Thus, cross-sectional imaging, in particular MRI, is needed to determine areas of disease infiltration. NPC has been shown to spread in a stepwise pattern along privileged pathways, such as the neuroforamina (Liang et al., 2009). In addition, involvement of critical structures located near the NP - including the cavernous sinus, pituitary gland, orbit and brainstem - must be evaluated to guide appropriate treatment and to spare these structures of the radiation dose if they are clear of disease $(\mathrm{Yu}$ et al., 2010). In the case of intensity-modulated RT (IMRT), CT is also required to correctly calculate dose based on absorption rates (Glastonbury, 2007).

Follow-up evaluation involves a baseline imaging study that is typically performed 2 to 3 months after completion of radiation treatment, followed by imaging every 3 to 6 months for the first 2 post-treatment years (Glastonbury, 2007). Any soft tissue signal abnormalities on MRI in the nasopharynx, deep face, or skull base should remain stable over this period or show further reduction in volume. Recurrent disease is seen as any increase in the bulk of abnormal signal from baseline imaging. Most recurrences, local or systemic, occur within the first 2 years after treatment (Glastonbury, 2007). Of patients with recurrences, $10 \%$ to $20 \%$ may be curable with additional treatment (Glastonbury, 2007). After 2 years without evidence of recurrence, the imaging interval is typically extended to every 6 to 12 months. Although not yet the mainstay of treatment, one meta-analysis demonstrated that FDG$\mathrm{PET} / \mathrm{CT}$ is more sensitive and specific than CT and MRI for the diagnosis of local residual or recurrent NPC (Liu et al., 2007).

\subsection{MRI technique}

The staging MRI protocol for NPC varies from center to center. In general, the images should cover the area from above the frontal sinuses to the thoracic inlet on axial studies and from the tip of the nose to the fourth ventricle on coronal sequences. At our institution, axial and coronal T1- and T2-weighted images, as well as a sagittal T1 or T2 fat saturation series covering the entire head and neck are obtained. A head and neck imaging coil is routinely used for both the $1.5 \mathrm{~T}$ and 3.0T MRI scanners. The axial, coronal and sagittal T1 series are performed using a T1-FLAIR technique. Postgadolinium-enhanced axial images with fat saturation and coronal images without fat saturation are also acquired using a conventional spin echo T1 technique. Lau et al. found that the axial precontrast and postcontrast series were the most informative MRI sequences for evaluating primary tumour extension and achieved approximately $100 \%$ diagnostic accuracy in T-staging of NPC (Lau et al., 2004). We find that axial and coronal noncontrast T1-weighted images are 
the best for providing detailed views of the local NP anatomy and surrounding structures, whereas postcontrast images allow for accurate assessment of perineural disease along major nerves, such as the maxillary and mandibular divisions of the trigeminal nerve, as well as the cavernous sinus (Yu et al., 2010).

\subsection{Comparison of imaging methods}

\begin{tabular}{|c|c|c|c|}
\hline & MRI & CT & PET/CT \\
\hline Strengths & $\begin{array}{l}\text { Superior to CT and } \\
\text { PET/CT for assessing } \\
\text { primary tumour } \\
\text { invasion into } \\
\text { surrounding soft tissue } \\
\text { and boney structures, } \\
\text { pharyngobasilar fascia } \\
\text { invasion, invasion into } \\
\text { the sinus of Morgagni, } \\
\text { skull base invasion, } \\
\text { intracranial invasion, as } \\
\text { well as cavernous sinus } \\
\text { extension and } \\
\text { perineural disease (Liao } \\
\text { et al., 2008; Ng et al., } \\
\text { 2009 Sakata et al., 1999) } \\
\text { Superior to CT and } \\
\text { PET/CT for evaluating } \\
\text { retropharyngeal } \\
\text { adenopathy } \\
\text { No exposure to } \\
\text { ionizing radiation }\end{array}$ & $\begin{array}{l}\text { Relatively } \\
\text { inexpensive } \\
\text { Rapid image } \\
\text { acquisition time } \\
\text { Widely available }\end{array}$ & $\begin{array}{l}\text { Superior to MRI and CT for } \\
\text { assessing lymph node } \\
\text { metastasis, especially } \\
\text { cervical nodal metastases, } \\
\text { and distant metastases, } \\
\text { especially occult metastatic } \\
\text { disease (i.e., N- and M- } \\
\text { staging of NPC) (Comoretto } \\
\text { et al., 2008; King \& Bhatia, } \\
\text { 2010; King et al., 2008; Lin et } \\
\text { al., 2008; Ng et al., 2009, } \\
\text { Wang et al., 2007) } \\
\text { Screens the entire patient } \\
\text { for local recurrence, lymph } \\
\text { node metastases and distant } \\
\text { metastases during a single } \\
\text { whole-body examination } \\
\text { using a single injection of } \\
\text { FDG } \\
\text { Significantly better } \\
\text { sensitivity and specificity } \\
\text { compared to CT and MRI } \\
\text { for diagnosis of local } \\
\text { residual or recurrent } \\
\text { nasopharyngealcarcinoma } \\
\text { (Liu et al., 2007) }\end{array}$ \\
\hline Weaknesses & $\begin{array}{l}\text { Expensive } \\
\begin{array}{l}\text { Long image acquisition } \\
\text { times compared to CT }\end{array} \\
\begin{array}{l}\text { Less readily available } \\
\text { compared to CT not } \\
\text { always reliable in } \\
\text { distinguishing between } \\
\text { enhancing residual }\end{array} \\
\end{array}$ & $\begin{array}{l}\text { Less accurate than } \\
\text { MRI and PET/CT for } \\
\text { evaluating tumour } \\
\text { invasion into } \\
\text { surrounding tissues } \\
(\mathrm{Ng} \text { et al., 2009) } \\
\text { Exposure to ionizing } \\
\text { radiation }\end{array}$ & $\begin{array}{l}\text { Accessibility issues (in some } \\
\text { regions) } \\
\text { Expensive } \\
\text { Exposure to ionizing } \\
\text { radiation } \\
\text { Compared to MRI, PET/CT } \\
\text { undermaps the }\end{array}$ \\
\hline
\end{tabular}




\begin{tabular}{|l|l|l|}
\hline $\begin{array}{l}\text { disease versus } \\
\text { posttherapy changes } \\
\text { due to treatment- } \\
\text { related edema, fibrosis, } \\
\text { inflammation, and } \\
\text { scarring (Comoretto et } \\
\text { al., 2008) }\end{array}$ & $\begin{array}{l}\text { Treatment-related } \\
\text { edema, fibrosis, } \\
\text { inflammation, and } \\
\text { scarring limit ability } \\
\text { to diagnose residual } \\
\text { or recurrent disease }\end{array}$ & $\begin{array}{l}\text { involvement of the } \\
\text { nasopharyn, skull base, } \\
\text { intracranial disease, } \\
\text { perineural spread, } \\
\text { parapharyngeal space, and } \\
\text { brain (due to high FDG } \\
\text { uptake by the brain) } \\
\text { (Comoretto } \text { et al., 2008; King } \\
\text { et al., 2008; Ng } \text { et al., 2009) } \\
\text { Inferior to MRI for } \\
\text { detecting retropharyngeal } \\
\text { lymph node metastases (Ng } \\
\text { et al., 2009; Ng } \text { et al., 2010, } \\
\text { Su et al., 2006) } \\
\text { False-positive and false- } \\
\text { negative related to } \\
\text { inflammatory hyperplastic } \\
\text { nodes, nodes with large } \\
\text { areas of necrosis, small } \\
\text { nodes that are beyond the } \\
\text { spatial resolution limits of } \\
\text { PET (Ng et al., 2009; Zhang } \\
\text { et al., 2006) }\end{array}$ \\
\hline
\end{tabular}

\section{Anatomy of the nasopharynx}

The nasopharynx is at the superior and posterior aspect of the aerodigestive tract. The nasopharyngeal mucosa is lined with squamous epithelium and surrounded by a muscular and fascial sling consisting of the superior constrictor muscle and the buccopharyngeal fascia derived from the middle layer of the deep cervical fascia. The space has three walls and a roof. It opens anteriorly to the posterior nasal cavity via the posterior nasal choanae, and inferiorly into the oropharynx at the level of the hard palate. On imaging, the $\mathrm{C} 1 / 2$ junction is also an accepted marker between the nasopharynx and oropharynx (Dubrulle $e t$ al., 2007). The roof of the nasopharynx abuts the sphenoid sinus floor, and slopes posteroinferiorly along the clivus/basiocciput to the upper cervical vertebrae. Remains of adenoid tissue may persist into adulthood and exist as tags in the roof of the nasopharynx.

The pharyngobasilar fascia (PBF), a tough aponeurosis connecting the superior constrictor muscles to the skull base, is perhaps the most important structure of the nasopharynx. The tough fibers of the pharyngobasilar fascia create a framework that determines the configuration of the nasopharynx and the support by which the entire pharynx hangs from the skull base (Dillon et al., 1984). The parallel lateral walls of the pharyngobasilar fascia extend from the posterior margin of the medial pterygoid plate anteriorly to the occipital pharyngeal tuber and prevertebral muscles posteriorly. The foramen lacerum, which is 
within the confines of the pharyngobasilar fascia, is a fibrocartilaginous structure that forms part of the floor of the horizontal carotid canal and roof of the nasopharynx. It provides a route for nasopharyngeal tumors to access the cavernous sinus and intracranial cavity. The pharyngobasilar fascia is a fibrous structure and occasionally can be seen as a thin dark line on T2-weighted axial MR images, deep to the submucosal tissues of the nasopharynx (Figure 3).

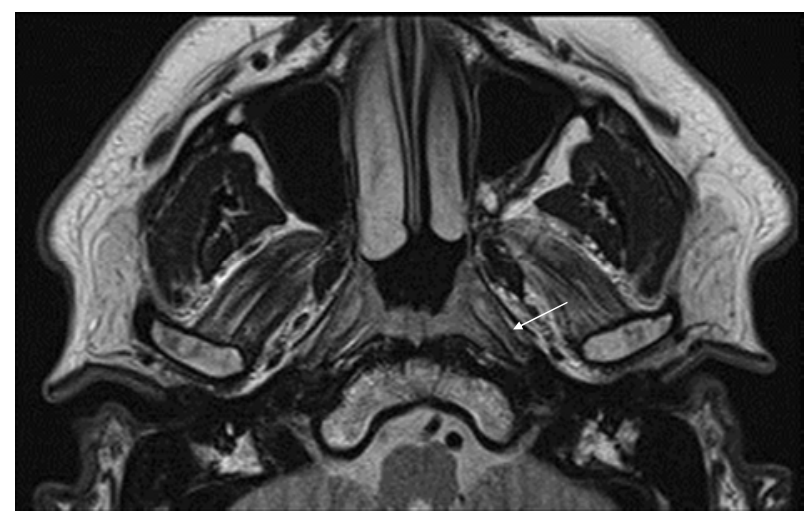

Fig. 3. Axial T2 weighted image at the level of the nasopharynx. The arrow shows the pharyngobasilar fascia on the left side.

The paired Eustachian tubes, along with the medial fibers of the levator veli palatini muscle pass into the nasopharynx via the sinus of Morgagni, a posterolateral defect in the pharyngobasilar fascia. The opening of the Eustachian tube is anterior (on axial images) and inferior (on coronal images) to the torus tubarius, the distal cartilaginous end of the eustachian tube that forms a mucosal-lined structure projecting into the lumen of the nasopharynx from the superior aspect of the posterior lateral nasopharyngeal walls. The fossa of Rosenmüller, otherwise known as the lateral pharyngeal recess, is posterior (on axial images) and superior (on coronal images) to the torus tubarius. The fossa of Rosenmüller is the most common site of origin of NPC (Goh \& Lim, 2009) (Figure 4). However, asymmetry of the lateral pharyngeal recesses is a common and normal incidental finding, and should not be mistaken as tumours.

Lateral to the nasopharynx is the parapharyngeal space (PPS), a fibrofatty space which separates the nasopharynx from the masticator space (Figure 4). Involvement of the parapharyngeal fat serves as an important marker of tumour infiltration used in staging. The posterolateral boundary of the nasopharynx consists of the carotid space (post-styloid parapharyngeal space), which is located posterior to the parapharyngeal space. Located posterior to the nasopharynx, between the nasopharyngeal mucosal space and the prevertebral muscles, is the retropharyngeal space, a potential space that contains the medial and lateral retropharyngeal lymph nodes. The lateral retropharyngeal nodes, also 
known as the nodes of Röuviere, are the first nodes in the lymphatic drainage of the nasopharynx and, along with the cervical Level II nodes, are reported to be the most common site of nodal metastases (Wang et al., 2009). The lateral retropharyngeal lymph nodes can be identified on MRI from the skull base to the level of C3 (King \& Bhatia, 2010). The medial retropharyngeal nodes do not form a discrete nodal chain, and thus, are less often visible on imaging.

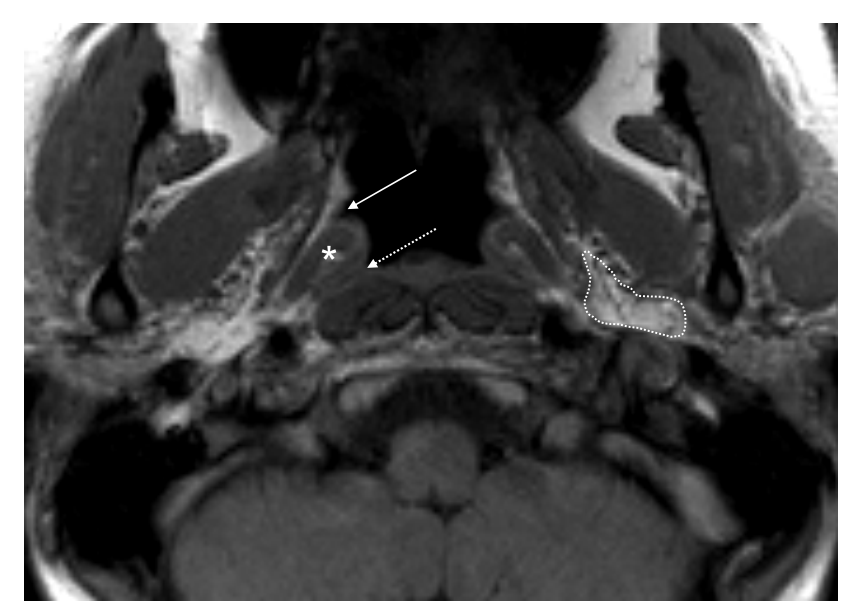

Fig. 4. Axial T1 image shows the torus tubarius (*). The solid arrow points to the opening of the Eustachian tube. Dashed arrow is the fossa of Rosenmuller. The dashed area shows the fat in the left prestyloid parapharyngeal space.

Other important structures include the foramen rotundum and pterygoid (or Vidian) canal, which communicate with the pterygopalatine fossa and are potential routes of tumour spread.

\section{Staging of NPC}

After the initial diagnosis of NPC is made on history, physical examination, and biopsy, cross-sectional imaging is required for cancer staging. Currently, the 7 th edition of the International Union Against Cancer (UICC) and American Joint Committee on Cancer (AJCC) TMN staging system is used, which was recently revised and released on 1 January 2010. As previously described, most cases of NPC originate in the lateral pharyngeal recess and spread submucosally with early infiltration into deeper neck spaces. NPC tends to have well-defined patterns of spread. 


\section{TMN Staging of}

Nasopharyngeal Carcinoma

Overview

\section{Primary Tumor $(\mathrm{T})$}

T1 Tumor confined to the nasopharynx, or extends to oropharynx and/or

T1 nasal cavity without parapharyngeal extension*

T2 Tumor with parapharyngeal extension'

T3 Tumor involves bony structures of skull base and/or paranasal sinuses

Tumor with intracranial extension and/or involvement of involvement

T4 of cranial nenves, hypopharynx orbit, or with extension to the intratemporal fossa/masticator space

- Parapharyngeal extension denotes posterolateral infiltration of tumor.

\section{Regional Lymph Nodes (N)}

NX Regional lymph nodes cannot be assessed

NO No regional lymph node metastasis

Unilateral metastasis in lymph node(5), $6 \mathrm{~cm}$ or less in greatest

NI dimension, above the supraclavicular lossa, andlor unitateral or bilateral, retropharyngeallymph nodes, $6 \mathrm{~cm}$ or less, in greatest dimension*

N2 Bilateral metastasis in lymph node(s), $6 \mathrm{~cm}$ or less in greatest dimension, above the supraclavicular fossa*

N3 Metastasis in a lymph noda $(\mathrm{s})^{*}>6 . \mathrm{cm}$ and/or extension to supraciavicular fossa

N3a Greater than $6 \mathrm{~cm}$ in dimension

N3b Extension to the supractavicular fossa

- Midline nodes are considered ipsilateral nodes.

\section{Distant Metastasis (M)}

MX Distant metastasis cannot be assessed

MO No distant metastasis (no pathologic M0; use clinical $M$ to complete stage group)

M1 Distant metastasis

\section{AJCC Stage Groupings}

\begin{tabular}{|c|c|c|c|}
\hline Stage 0 & TIS. NO, MO & \multirow{3}{*}{ Stage IVA } & I4, NO, MO \\
\hline Stage 1 & TÁ NO, MO & & T4, NT, MO \\
\hline \multirow{3}{*}{ Stage II } & T1, N1, MO & & $\mathrm{T} 4, \mathrm{~N} 2, \mathrm{MO}$ \\
\hline & T2. NO, MO & Stage IVB & Any T N3 Mo \\
\hline & T2. N1. MO & Stage IVC & Any T, Any N, M1 \\
\hline \multirow{5}{*}{ Stage III } & T1. N2, MO & & \\
\hline & T2. N2. MO & & \\
\hline & T3, NO, MO & & \\
\hline & T3, N1, MO & & \\
\hline & T3, N2, MO & & \\
\hline
\end{tabular}

Box 1 . 


\subsection{T1 NPC}

Stage T1 refers to disease that is localized to the nasopharynx, as well as disease that has extended inferiorly into the oropharynx or anteriorly into the nasal cavity (Lee,2004; Liu et al., 2008; Yu et al., 2010). Disease that is isolated to the NP is described as being superficial to the pharyngobasilar fascia (PBF). In this case, there is no evidence of tumour breaching or crossing the PBF barrier, which occasionally can be identified on T2-weighted studies as a thin dark curvilinear line running from the medial pterygoid plate laterally and following the contour of the longus musculature along the back wall of the NP (Figure 3). The tumour appears as a hypointense to isointense mass on T1-weighted imaging that enhances to a lesser degree than normal mucosa (Chin et al., 2003).

Oropharyngeal extension is readily noted on coronal or sagittal MR imaging as tumour that has extended inferiorly past the plane of palate (Figure 5). On axial sections, the oropharynx is considered involved when tumour is seen inferior to the $\mathrm{C} 1 / \mathrm{C} 2$ junction.

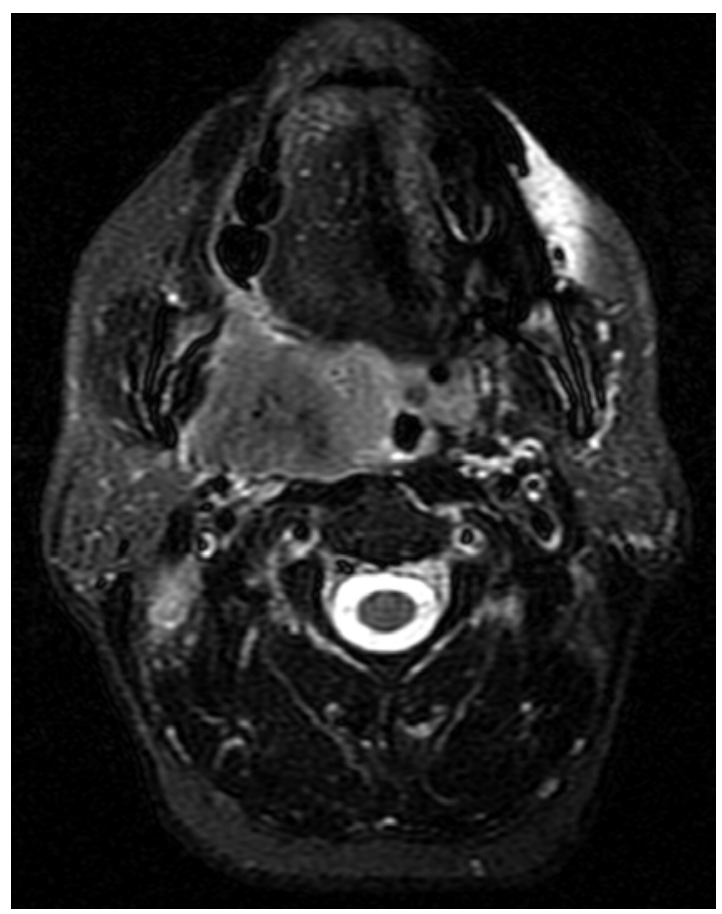

Fig. 5. Axial image of a patient with NPC that shows disease that has extended down to the level of the right oropharynx.

In addition, stage $\mathrm{T} 1$ disease comprises anterior extension past the plane of the posterior choana into the nasal cavity (Figure 6). From the nasal cavity, NPC can invade through the sphenopalatine foramen into the pterygopalatine fossa (stage T3 disease), resulting in obliteration of the normal fat content in this fossa (Figure 7). Direct extension from the nasal cavity is the most common route of NPC invasion into the pterygopalatine fossa, followed 
by extension from the ethmoid and/or sphenoid sinuses. The significance of pterygopalatine fossa involvement is described later (T3 NPC).

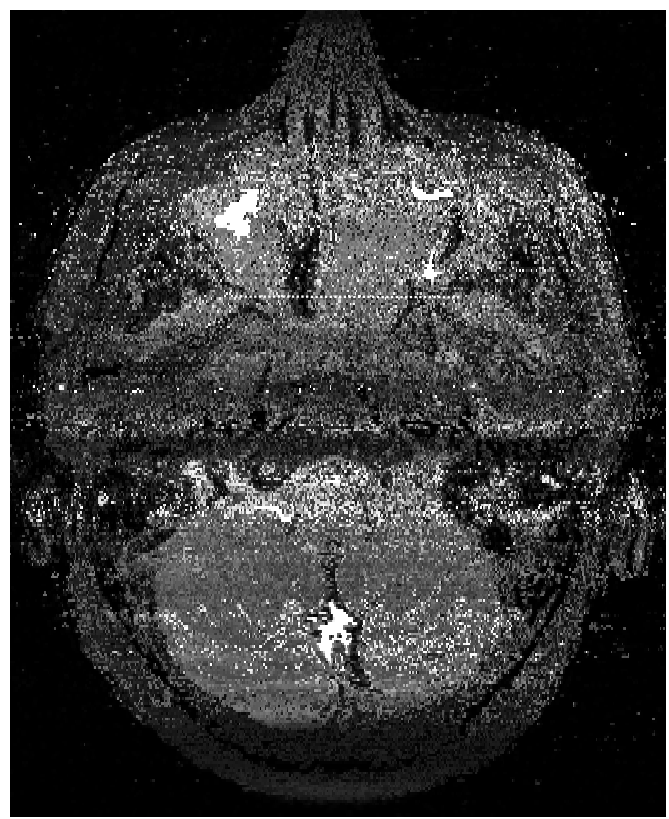

Fig. 6. NPC which has extended beyond the plane of the posterior choana (dashed line) into the nasal cavity.

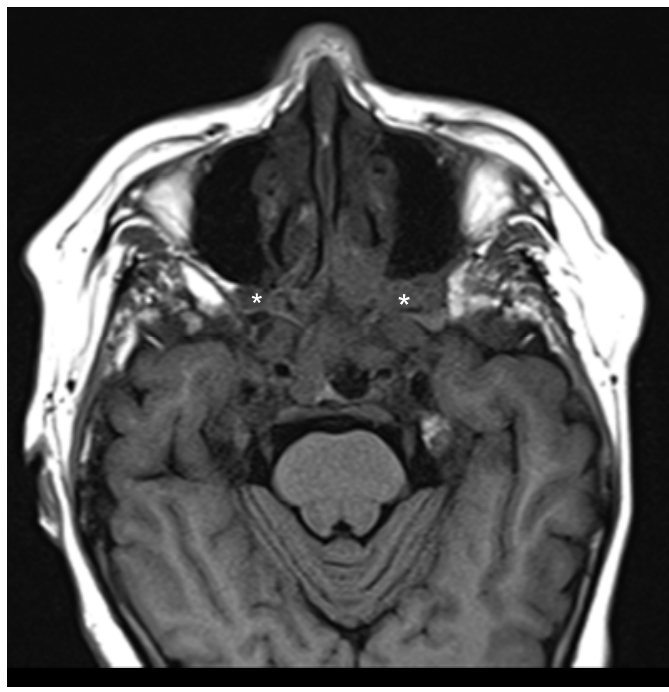

Fig. 7. Axial T1 weighted image shows abnormal soft tissue filling the right and left pterygopalatine fossae $\left(^{*}\right)$. 


\subsection{T2 NPC}

Disease that has spread beyond the PBF and infiltrated posterolaterally into the parapharyngeal space (PPS) is considered stage T2. This can lead to compression of the Eustachian tube, resulting in middle ear and mastoid effusion (King \& Bhatia, 2010). PPS invasion is associated with worse disease control and survival rates, as well as increased rate of distant metastases compared to stage T1 (Cheng et al., 2005; Chua et al., 1996; Ho et al., 2008; Teo et al., 1996). On imaging, key components of the PPS include the tensor veli palatini and levator palatine muscles. PPS involvement is recognized as a disruption or attenuation of the PBF, infiltration of the tensor veli palatini, or breach of the intrapharyngeal portion of the levator veli palatini muscle.

Infiltration of the fatty component of the PPS is visible on T1-weighted imaging as an intermediate signal mass invading into the hyperintense fat of the PPS (Figure 8). As the disease progresses, the full thickness of the intrapharyngeal portion of the levator veli muscle and the tensor veli palatini muscle (appearing as a thin strip of muscle just lateral to the levator veli palatini) may also become involved, followed by infiltration of the normally pristine fat of the prestyloid PPS, which is located deep to the tensor muscle. With further posterolateral spread, the poststyloid PPS structures, such as the carotid sheath, also become vulnerable to disease (Figure 9).

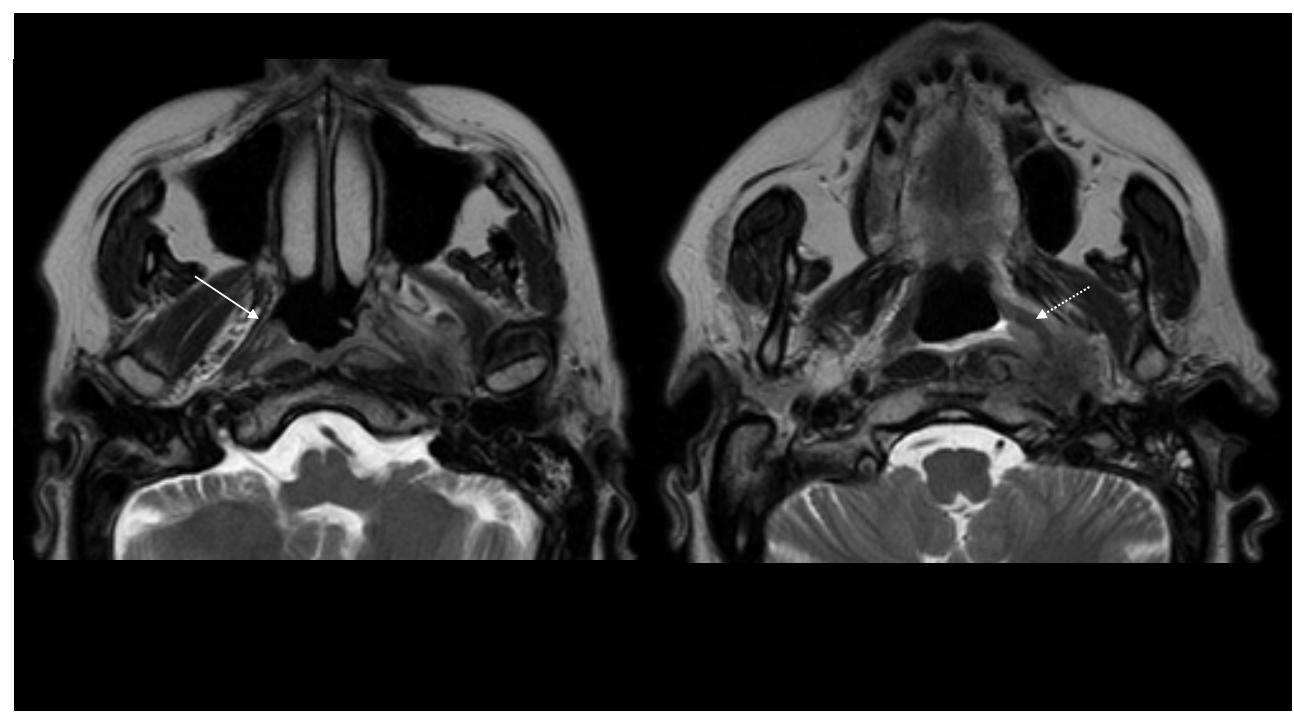

Fig. 8. Axial T2 weighted images shows a carcinoma that has infiltrated lateral to the tensor and levator veli palatini. Solid arrow shows normal tensor veli palatini on the right. Dashed arrow shows the abnormal left levator muscle which is being displaced and the presence of tumor lateral to it. 


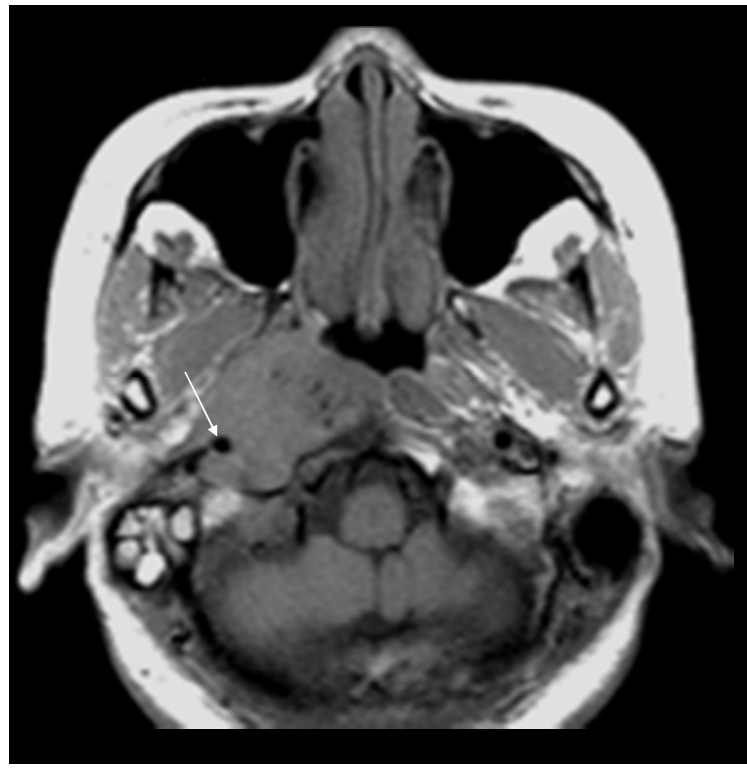

Fig. 9. Axial T1 image shows a large right sided NPC that has extended to encase the right internal carotid artery (arrow).

\subsection{T3 NPC}

Stage T3 disease is characterized by involvement of the paranasal sinuses and/or the central skull-base structures. Skull base invasion is seen in up to $60 \%$ of NPC patients at diagnosis (King et al., 1999; Roh et al., 2004), with the most common sites of involvement being the clivus, pterygoid bones, body of the sphenoid bone, and apices of the petrous temporal bones (King \& Bhatia, 2010). In addition, the number of sites involved within the skull base may have prognostic significance (Lu et al., 2004). Assessment of the skull base should focus on five key regions: clivus, right pterygoid base, left pterygoid base, right petrous apex, and left petrous apex (King \& Bhatia, 2010). On axial T1-weighted MR sequences, bony skull base disease is detected as a loss of the hyperintense signal, which is characteristic of normal fatty yellow bone marrow. It is replaced with an intermediate signal indicative of either bony reaction or actual invasion. NPC commonly invades posteriorly into the clivus (Figure 10). Although normal clival marrow may appear heterogeneous on T1-weighted images, it should still appear more intense than the pons (Goh \& Lim, 2009). In addition, up to $25 \%$ of patients have tumour spread superiorly into the floor of the sphenoid sinus, often extending up into the sphenoid sinus cavity (Chong \& Fan, 1993; Goh \& Lim, 2009) (Figure 11). The body of the sphenoid is more difficult to assess and may be best studied on coronal images (King \& Bhatia, 2010). The sphenoid wings and upper cervical spine should also be assessed. CT scans may also have a role in detecting the presence of cortical erosion and bony sclerosis, which reflects reactive changes due to tumour invasion. It is important, however, to note that sclerosis is a non-specific sign that may arise from adjacent sinus disease, particularly in the sinus margins and the pterygoids. 


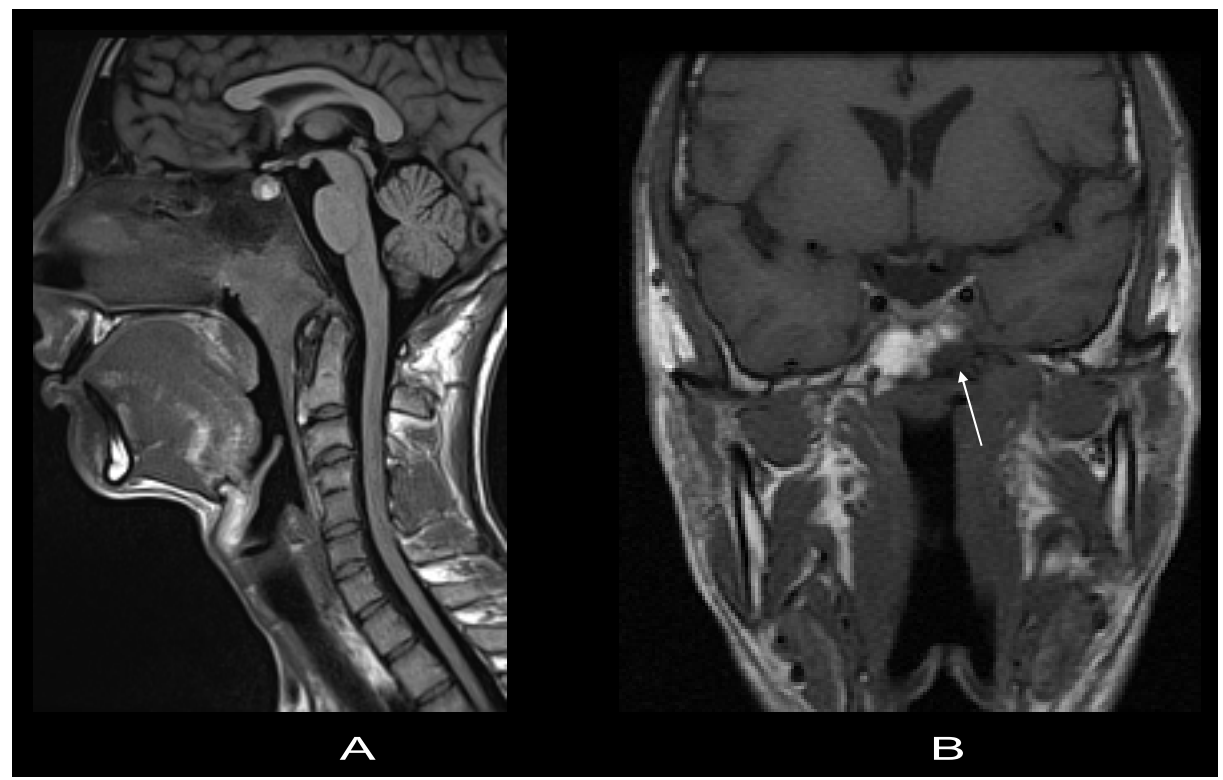

Fig. 10. 10A is a sagittal T1 image that shows NPC invasion into the clivus. There is a loss of the inferior cortical margin of the clivus. The clivus is also of uniform lower signal that reflects sclerotic change. 10B is as coronal T1 image in another patient that shows NPC infiltration into the left aspect of the clivus (arrow).

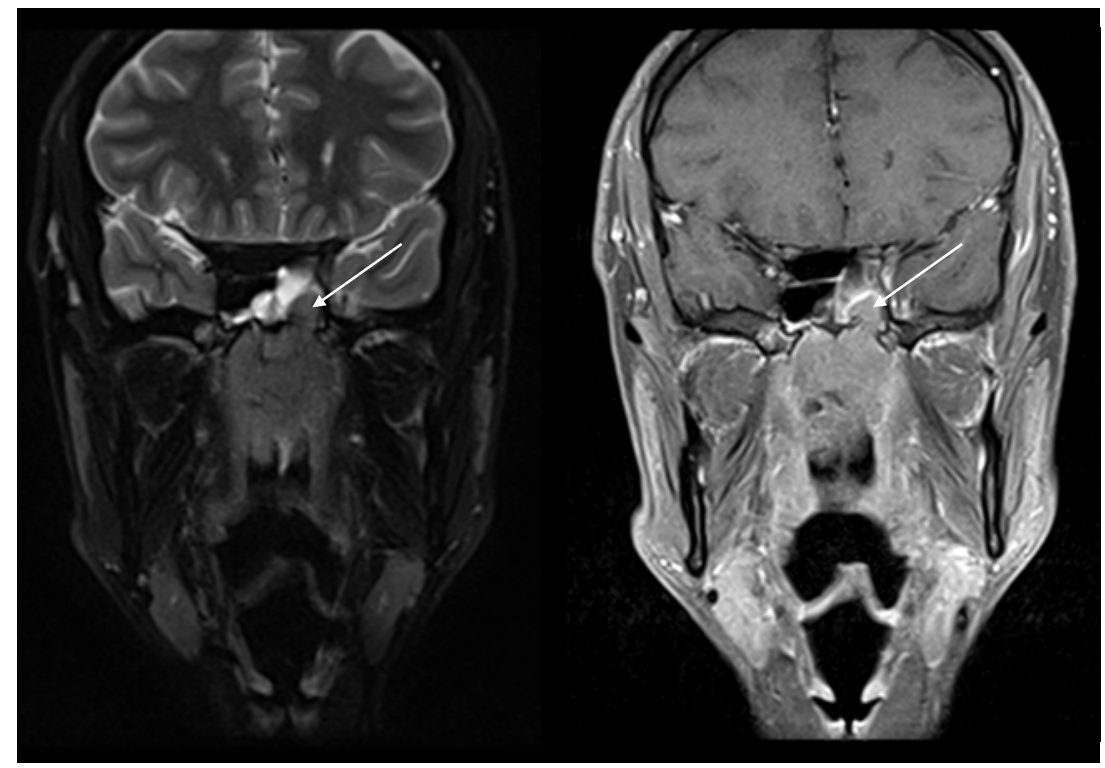

Fig. 11. Coronal T2 (left) and post gadolinium enhanced T1 (right) weighted images show superior extension of NPC through the floor of the sphenoid sinus (arrows). 
Next, the skull base foramina and fissures - which include the foramen rotundum (V2 nerve), the vidian canal (vidian nerve), the foramen ovale (V3 nerve), and foramen lacerum - should be examined. Nerve involvement signifies stage T4 disease (see section below). The foramen ovale and lacerum are common routes of tumour extension into the intracranial cavity (King \& Bhatia, 2010). While the skull base foramina present an unobstructed route for tumor spread, direct invasion of the bone bordering these foramina is also a common finding. The skull base foramina are best assessed on coronal images. Less common findings include inferior spread of tumor to involve the hypoglossal nerve canal (XII nerve) and jugular foramen (IX-XI nerves) (King \& Bhatia, 2010).

It is important to differentiate tumour spread into the paranasal sinuses - which include the ethmoid sinuses, sphenoid sinuses, and maxillary sinuses - from benign mucosal inflammatory changes, which are common in patients with NPC. On MRI, mucosal thickening can be distinguished from NPC by a greater uniform T2-weighted signal and a marked degree of contrast enhancement. With tumor invasion into the ethmoid sinuses, which usually occurs via direct spread from the sphenoid sinus or nasal cavity, there is a reduced chance of shielding the optic nerve from the radiation dose in RT. Involvement of the sphenoid sinus, which is separated from the nasopharynx by only a thin plate of bone, is a common finding (Figure 11). In contrast, anteroinferior tumour invasion into the maxillary sinuses is a rare event, except in late disease where there is usually extensive invasion throughout the nasal cavity, other paranasal sinuses, skull base, and brain (King et al., 1999). Sinus involvement is seen on imaging as a loss of contiguity of the sinus walls.

\subsection{T4 NPC}

T4 disease is denoted by intracranial extension and/or involvement of the cranial nerves, hypopharynx, orbit, or masticator space. Unchecked, NPC can extend superiorly into the cavernous sinus and dura (Figure 12), while direct invasion of the brain is rare at diagnosis (King \& Bhatia, 2010). There are multiple routes into the cavernous sinus, including extension from tumour surrounding the horizontal portion of the internal carotid artery or cranial nerve V3, as well as extension from the orbital fissures or the skull base in the region of the foramen ovale or sphenoid sinus (King \& Bhatia, 2010). Within the cavernous sinus, cranial nerves III, IV, V1, V2, and VI are vulnerable to tumour invasion. Their involvement is manifested clinically through an abnormal neurological examination, as well as by signs and symptoms of various cranial nerve palsies, including extraocular muscle dysfunction, facial pain, paresthesia and numbness. True perineural spread, however, is uncommon in the pre-treatment setting (King \& Bhatia, 2010). Prognostically, cranial nerve involvement has been shown to be associated with a higher rate of distant metastases and decreased survival (Yu et al., 2010). Radiologically, postcontrast T1-weighted MR sequences with fat saturation are used to assess for cranial nerve involvement, especially for V2 along foramen rotundum (Figure 13) and V3 in the foramen ovale (Figure 14). Contrast-enhanced MRI shows perineural disease extension and cavernous sinus involvement as asymmetric nodular thickening and abnormal enhancement. Skip lesions may also be noted. A late sequelae is expansion of the bony canals in which these nerves travel. 


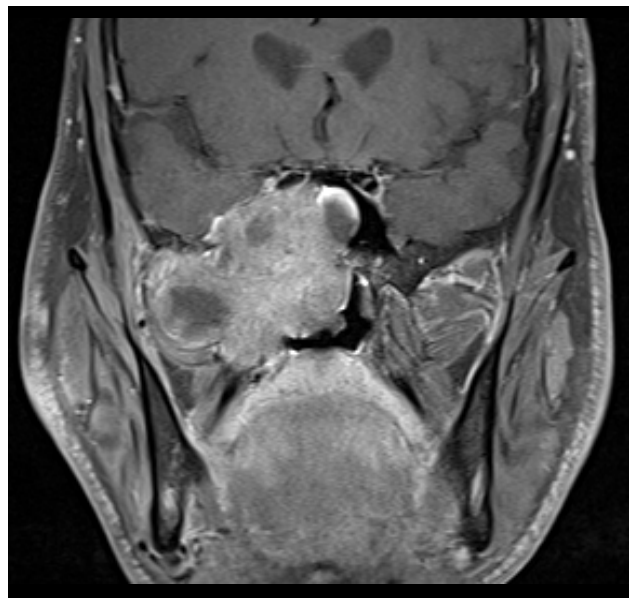

Fig. 12. Coronal postcontrast study shows a large NPC that has extended laterally into the right masticator space as well as superiorly to invade the cavernous sinus, sphenoid sinus and cause mass effect upon the right temporal lobe.

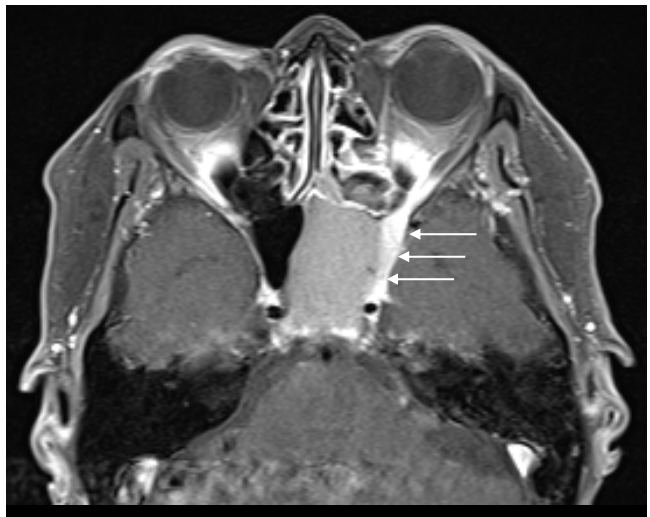

Fig. 13. Axial image shows asymmetric thickening and enhancement along the left V2 nerve (arrows).

Orbital invasion, usually arising from the pterygopalatine fossa via the inferior orbital fissure or directly from the cavernous sinus, denotes the most extensive form of disease (King \& Bhatia, 2010) (Figure 15). From the PPS, pterygoid base, or pterygomaxillary fissure, NPC can extend laterally to involve masticator space, which includes the medial and lateral pterygoid muscles, temporalis muscle, infratemporal fat, as well as the mandibular division (V3) of the trigeminal nerve (Figure 14). Disease involving the masticator space can give rise to trismus and weakness in mastication. In addition, the V3 nerve is vulnerable to tumour infiltration within the masticator space. Both antegrade and retrograde perineural spread along V3 is possible. From the masticator space, NPC can also extend superiorly through the floor of the middle cranial fossa and foramen ovale to gain access to the intracranial cavity and the cavernous sinus. 


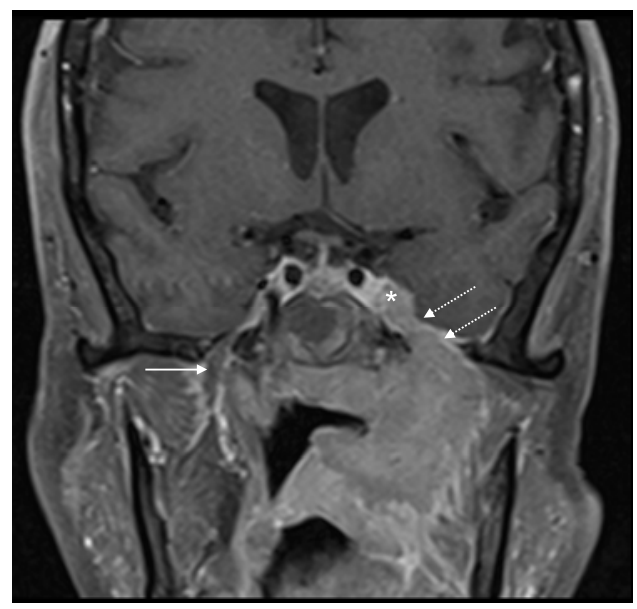

Fig. 14. Coronal image shows NPC that has extended laterally into the left masticator space and subsequent perineural tumor tracking superiorly (dashed arrows) along V3 into the left cavernous sinus $\left(^{*}\right)$. Solid arrow shows the normal contralateral V3 nerve.

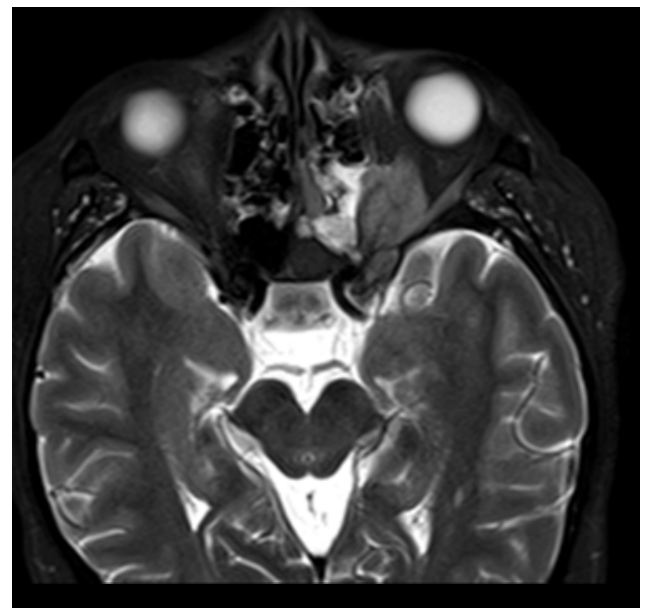

Fig. 15. Axial T2 weighted scan shows intermediate signal tumor that has extended through the superior orbital fissure into the left orbit.

The hypopharynx, which is the most inferior site included in the TMN staging classification, is very rarely involved at diagnosis due to the tendency of NPC to extend superiorly rather than inferiorly (King \& Bhatia, 2010).

\subsection{Nodal stage}

The NPC N classification system differs from other head and neck mucosal malignancies (see Box 1). Up to $60-90 \%$ of NPC patients will have nodal metastases at presentation (Glastonbury, 2007; Goh \& Lim, 2009), suggesting that only 10-40\% of cases present 
without positive nodal disease (N0). Positive neck nodal disease in NPC is associated with an increased risk of local recurrence and distant metastases (Goh \& Lim, 2009). Unlike other head and neck squamous cell carcinomas, nodal disease in NPC is more frequently bilateral.

NPC generally follows a very orderly pathway of nodal spread, beginning with the (lateral) retropharyngeal lymph nodes (RPN) (Figure 16) - located medial to the carotid artery before involving nodal groups along the internal jugular chain (level II to IV), spinal accessory chain (Va and Vb), as well as supraclavicular nodes (Glastonbury, 2007; King et al., 2004). Level IIa or b nodes, located posterior to the jugular vein in the upper neck, are the most common site for non-retropharyngeal node involvement (Mao et al., 2008) (Figure 17).

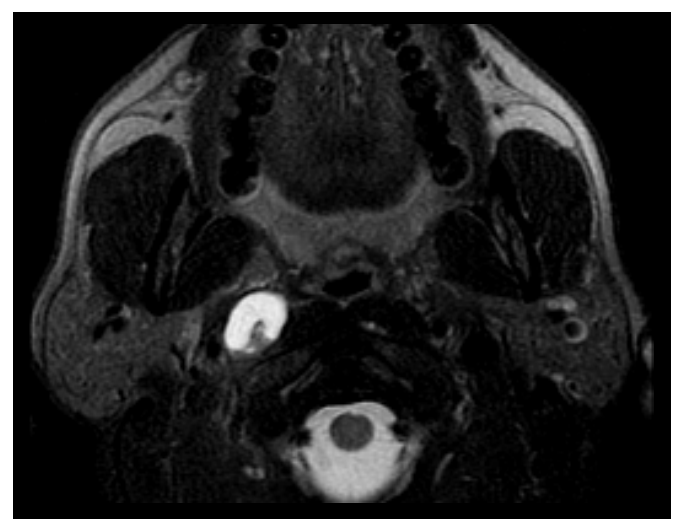

Fig. 16. Cystic right retropharyngeal lymph node.

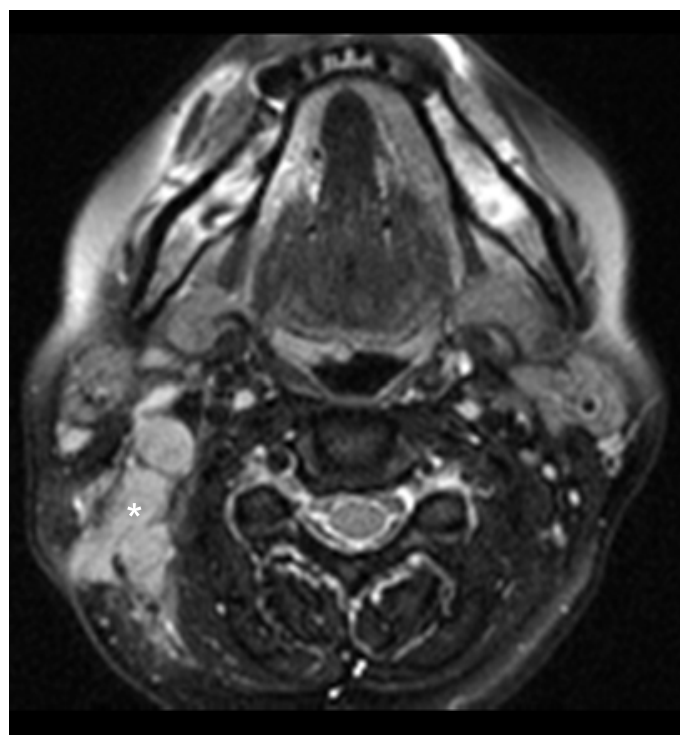

Fig. 17. Right sided level II adenopathy $\left(^{*}\right)$. 
Nodal disease in the submandibular and parotid/periparotid regions is a rare occurrence (Chong \& Fan, 2000; King \& Bhatia, 2010), but should be evaluated for radiotherapy planning purposes. Although the RPN are generally considered the first echelon of metastatic spread, studies have shown that this is not true in all cases (Liu et al., 2006; Mao et al., 2008; Ng et al., 2004; Wang et al., 2009). While King et al. found that the RPN were bypassed in only $6 \%$ of cases to preferentially affect the level II distribution, $\mathrm{Ng}$ et al. found that 17 of 89 cases of NPC bypassed the RPN (King et al., 2000; Ng et al., 2004). In addition, $\mathrm{Ng}$ et al. also reported skip metastases in the lower neck lymph nodes and the supraclavicular fossa in $7.9 \%$ of cases, and distant metastases to thoracic and abdominal nodes in 3-5\% of cases. After radiotherapy, level I nodes may also become involved (Ahuja et al., 1999).

In the current $\mathrm{N}$ classification system, N1 disease consists of the presence of unilateral metastasis in cervical lymph node(s) that are $6 \mathrm{~cm}$ or less in their greatest dimension, and/or unilateral or bilateral RPN metastasis that are $6 \mathrm{~cm}$ or less in their greatest dimension. Nodes greater than $3 \mathrm{~cm}$ in size are generally considered "nodal masses" and are indicative of confluent nodes. N2 disease is defined by bilateral metastasis in the cervical lymph node(s) that are again $6 \mathrm{~cm}$ or less in greatest dimension. Unlike other carcinomas in the neck, N2 is not further divided into substages. In both N1 and N2 stages, disease is restricted to above the supraclavicular fossa. Once supraclavicular fossa nodal involvement is noted, the disease is upstaged to N3b. Supraclavicular nodes include all lymph nodes seen on the same axial cross-sectional slice as a portion of the clavicle, and include Level IV and $\mathrm{Vb}$ nodes. Stage N3a disease is defined by matted nodes greater than $6 \mathrm{~cm}$ in their greatest dimension, although this is a rare finding (King \& Bhatia, 2010) (Figure 18).

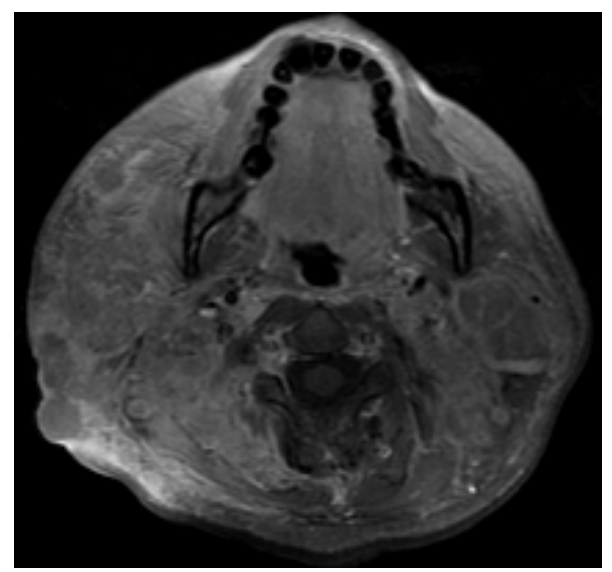

Fig. 18. Massive conglomerate right sided neck adenopathy measuring over $6 \mathrm{~cm}$ in dimension -N3a disease.

While distinguishing between the primary tumour mass and adjacent RPN is best assessed with MRI, cervical lymph nodes can be evaluated accurately with both MRI and CT (King et al., 2004). T2-weighted imaging with fat saturation shows nodes as bright structures in the posterior cervical fat (Figure 17). The higher resolution of CT facilitates the visualization of neck adenopathy, as well as nodal necrosis and extracapsular extension. The latter manifests 
as a loss or irregularity of the nodal margins, and/or streakiness of the adjacent fat (Yu et al., 2010). Patients with nodes showing necrosis and extranodal spread have a very poor prognosis with a 50\% decreased 5-year survival rate (Som et al., 1987).

There are several features on imaging that are suggestive of metastatic nodal disease, including a large size (although there is no accepted size criterion, generally $>1.5 \mathrm{~cm}$ for levels I and II, $>1 \mathrm{~cm}$ for levels for levels IV-VII, and $>5 \mathrm{~mm}$ for RPN using the shortest transaxial diameter is considered suspicious) (Goh \& Lim, 2009; King \& Bhatia, 2010), a group of 3 or more nodes borderline in size, rounded nodes with loss of the fatty hilum, and necrosis (King \& Bhatia, 2010). If identified, necrosis is considered $100 \%$ specific. However, due to resolution restrictions, necrosis can only be reliability identified in tumour foci greater than $3 \mathrm{~mm}$, of which approximately one-third reportedly have nodal necrosis (Goh \& Lim, 2009; Som \& Brandwein, 2003; Yousem et al., 1992). Necrosis or cystic change is hypointense on T1-weighted images with rim enhancement with contrast, and hyperintense on T2-weighted images (Figure 16). In CT images, necrosis is seen as a focal area of hypoattenuation with or without rim enhancement (Figure 19).

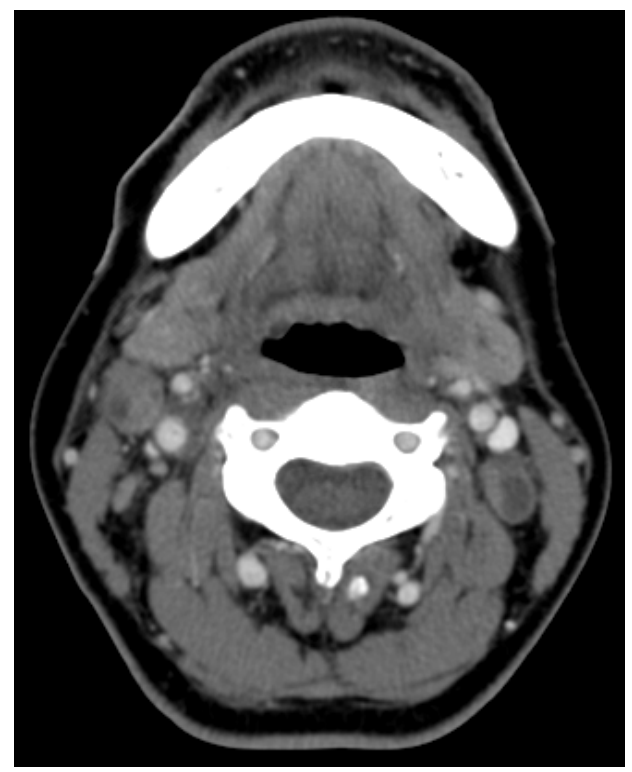

Fig. 19. Bilateral level II adenopathy. Focal areas of lower attenuation on CT is compatible with the presence of necrotic change.

\subsection{Distant metastasis (M)}

The M stage of NPC is similar to that of other malignancies, whereby M0 signifies the absence of distant metastasis and M1 refers to the presence of such disease. NPC has the highest incidence of distant metastasis among head and neck cancers, with a rate as high as $11 \%$ at diagnosis (Kumar et al., 2004; Teo et al., 1996). The likelihood of metastasis increases with increasing $\mathrm{T}$ and $\mathrm{N}$ stage. 
The most commonly affected regions are the bone, lung and liver (Chiesa \& De Paoli, 2001) (Figure 20). Thus, bones and lung apices should be evaluated for tumour involvement in head and neck MRI studies, especially in patients with risk factors such as metastatic cervical nodes which extend to the supraclavicular fossa (stage N3b).

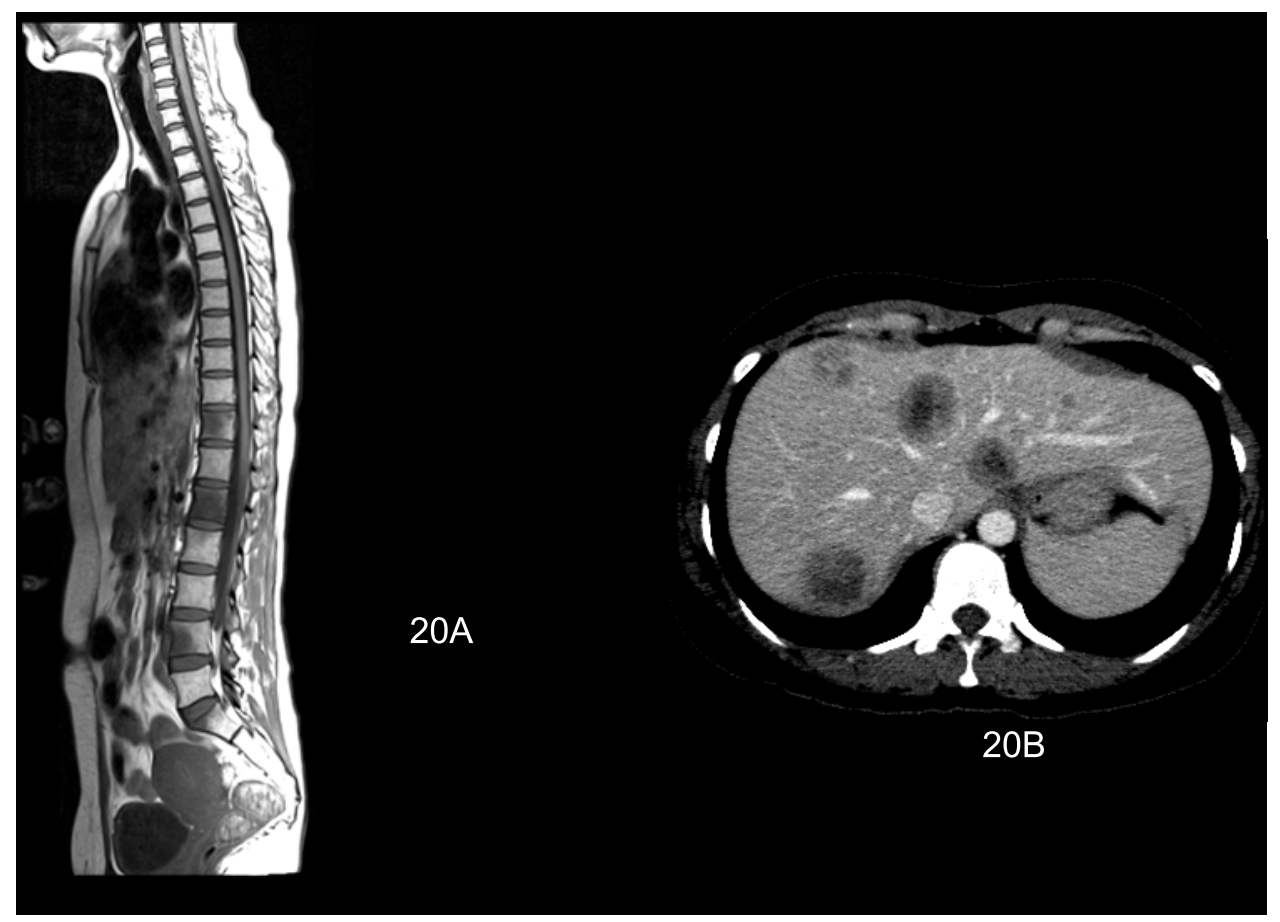

Fig. 20. A and B 20A is a sagittal T1 weighted exam of the spine showing multiple areas of abnormal intermediate signal within vertebral bodies in the lower thoracic and lumbar spine -bony metastases. 20B is a contrast CT of the abdomen that shows the presence of multiple liver metastases.

The presence of M1 disease is associated with shorter survival rates (Teo et al., 1996) and significantly alters patient management, as such patients are generally considered to be incurable. Median survival is under four months and approximately $90 \%$ of patients with distant metastases pass away within a year (Goh \& Lim, 2009; Khor et al., 1978). The goal of treatment in such instances will be palliation with therapy being applied for locoregional symptom control.

The exact method for the evaluation of distant metastasis will vary from institution to institution. Imaging options include bone scintigraphy, chest $\mathrm{x}$-ray, CT of the thorax, abdomen and pelvis, and PET/CT. Studies have shown fluorodeoxyglucose PET/CT imaging to have a higher sensitivity and specificity in detecting distant metastases (Chen et al., 2006; Chua et al., 2009; Comoretto et al., 2008; King et al., 2008; Lin et al., 2008; Liu et al., 2007; Ng et al., 2009; Wang et al., 2007; Yu et al., 2010). 


\section{Tumour volume}

Tumour volume has also been reported to have significant prognostic relevance outside of the TNM classification system (Wei \& Sham, 2005). There is an estimated 1\% increase risk of local control failure with every $1 \mathrm{~cm}^{3}$ increase in tumour volume. The increased risk is attributed to factors such as increase number of tumour clonogens, tumor hypoxia and relative radioresistance, etc (Bentzen et al., 1991; Johnston et al., 1995; Lartigau et al., 1993; Sze et al., 2004). However, issues with standardized methods of volume measurement, the intraand interobserver reliability due to operator-dependent tracing, as well as the technical challenges associated with implementing this in the clinical setting - including the time it takes to perform this tedious task - have prevented it from being routinely used in daily practice.

\section{Summary}

Nasopharyngeal carcinoma is a relatively rare neoplasm with a characteristic geographic and ethnic distribution. It most commonly arises in the lateral pharyngeal recess, and has a tendency to invade widely and metastasize. Cervical lymphadenopathy is very common at presentation and is a common presenting complaint.

Diagnosis of NPC can be made on endoscopically-guided biopsy, but effective treatment of NPC requires an accurate mapping of tumor volume and extent with imaging. Imaging allows for evaluation of tumour extent, including submucosal, osseous, and intracranial tumour spread which cannot be assessed clinically or endoscopically. Staging of NPC is based on the new 2010 AJCC guidelines. MRI is the best tool for assessing tumour extent under the current staging system, while high-resolution CT has value for assessing cortical bone erosion and PET/CT is emerging as the most accurate modality for assessing distant metastases and recurrence.

A thorough understanding of the anatomy of the nasopharynx and surrounding structures, as well as the natural history of the disease and patterns of spread, allows for accurate tumour mapping and treatment planning.

\section{References}

Ahuja AT, Leung SF, Teo P, Ying M, King W, Metreweli C (1999). Submental metastasis from nasopharyngeal carcinoma. Clin Radiol. 54:25-8.

Bentzen SM, Johansen LV, Overgaard J, Thames HD (1991). Clinical radiobiology of squamous cell carcinoma of the oropharynx. Int J Radiat Oncol Bio Phys. 206:11971206.

Brennan B (2006). Nasopharyngeal carcinoma. Orphanet Journal or Rare Diseases. 1:23.

Burt RD, Vaughan TL, McKnight B (1992). Descriptive epidemiology and survival analysis of nasopharyngeal carcinoma in the United States. Int J Cancer. 52:549 - 56.

Caglar M, Ceylan E, Ozyar E (2003). Frequency of skeletal metastases in nasopharyngeal carcinoma after initiation of therapy: should bone scans be used for follow-up? Nucl Med Commun. 24(12):1231 
Chang ET \& Adami HO (2006). The Enigmatic Epidemiology of Nasopharyngeal Carcinoma. Cancer Epidemiol Biomarkers Prev. 15:1765-1777.

Chang JT, Lin CY, Chen TM et al. (2005). Nasopharyngeal carcinoma with cranial nerve palsy: the importance of MRI for radiotherapy. Int. J. Radiat. Oncol. Biol. Phys. 63(5), 1354-1360.

Chen YK, Su CT, Ding HJ et al. (2006). Clinical usefulness of fused PET/CT compared with PET alone or CT alone in nasopharyngeal carcinoma patients. Anticancer Res. 26(2B), 1471-1477.

Cheng SH, Tsai SY, Yen KL, Jian JJ, Feng AC, Chan KY, Hong CF, Chu NM, Lin YC, Lin CY, Tan TD, Hsieh CY, Chong V, Huang AT (2005). Prognostic significance of parapharyngeal space venous plexus and marrow involvement: potential landmarks of dissemination for stage I-III nasopharyngeal carcinoma. Int J Radiat Oncol Biol Phys. 61: 456-465.

Chiesa F, De Paoli F (2001). Distant metastases from nasopharyngeal cancer. ORL J Otorhinolaryngol Relat Spec. 63(4):214.

Chin SC, Fatterpekar G, Chen CY, Som PM. (2003). MR imaging of diverse manifestations of nasopharyngeal carcinomas. Am. J. Roentgenol. 180(6), 1715-1722.

Chong VFH (2006). Neoplasms of the nasopharynx. In: Head and Neck Cancer Imaging. Baert AL, Sartor K (Eds). Springer, Berlin, Germany, 143-162.

Chong VFH, Fan YF (2000). Facial lymphadenopathy in nasopharyngeal carcinoma. Clin Radiol. 55:363-7.

Chong VFH, Fan YF (1993). MRI and CT assessment of paranasal sinus involvement in nasopharyngeal carcinoma. Clin Radiol. 48:345.

Chong VF, Fan YF, Khoo JB (1996). Nasopharyngeal carcinoma with intracranial spread: CT and MR characteristics. J. Comput. Assist. Tomogr. 20(4), 563-569.

Chua ML, Ong SC, Wee JT et al. (2009). Comparison of 4 modalities for distant metastasis staging in endemic nasopharyngeal carcinoma. Head Neck 31(3), 346-354.

Chua DT, Sham JS, Kwong DL, Choy DT, Au GK, Wu PM (1996). Prognostic value of paranasopharyngeal extension of nasopharyngeal carcinoma. A significant factor in local control and distant metastasis. Cancer. 78(2), 202-210.

Chung NN, Ting LL, Hsu WC, Lui LT, Wang PM (2004). Impact of magnetic resonance imaging versus $\mathrm{CT}$ on nasopharyngeal carcinoma: primary tumor target delineation for radiotherapy. Head Neck. 26(3), 241-246.

Comoretto M, Balestreri L, Borsatti E, Cimitan M, Franchin G, Lise M (2008). Detection and restaging of residual and/or recurrent nasopharyngeal carcinoma after chemotherapy and radiation therapy: comparison of MR imaging and FDG PET/CT. Radiology. 249(1), 203-211.

Dillon WP, Mills CM, Kjos B, et al (1984) Magnetic Resonance imaging of the nasopharynx. Radiology. 152:731-738.

Dubrulle F, Souillard R, Hermans R (2007). Extension patterns of nasopharyngeal carcinoma. Eur Radiol. 17:2622-2630

Glastonbury CM (2007). Nasopharyngeal Carcinoma The Role of Magnetic Resonance Imaging in Diagnosis, Staging, Treatment, and Follow-up. Top Magn Reson Imaging. 18:225-235. 
Goh J \& Lim K (2009). Imaging of Nasopharyngeal Carcinoma. Ann Acad Med Singapore. 38:809-816.

Henderson BE, Louie E, SooHoo Jing J, Buell P, Gardner MB. Risk factors associated with nasopharyngeal carcinoma. N. Engl. J. Med. 295(20), 1101-1106 (1976).

Ho HC, Lee MS, Hsiao SH et al (2008). Prognostic influence of parapharyngeal extension in nasopharyngeal carcinoma. Acta Otolaryngol. 128(7), 790-798.

Ho JHC (1978). An epidemiologic and clinical study of nasopharyngeal carcinoma. Int J Radiat Oncol Bio Phys. 4:183-205.

Johnston CR, Thames HD, Huang DT (1995). The tumour volume and clonogens number relationship: tumor control predictions based upon tumor volume estimates derived from computer tomography. Int J Radiat Oncol Biol Phys. 332:281-337.

Khor TH, Tan BC, Chua EJ, Chia KB (1978). Distant metastases in nasopharyngeal carcinoma. Clin Radiol. 29:27-30.

King AD, Ahuja AT, Leung SF et al (2000). Neck node metastases from nasopharyngeal carcinoma: MR imaging of patterns of disease. Head Neck. 22(3), 275-281.

King AD, Bhatia KSS (2010). Magnetic resonance imaging staging of nasopharyngeal carcinoma in the head and neck. World J Radiol. 2(5):159-165.

King AD, Lam WW, Leung SF, Chan YL, Teo P, Metreweli C (1999). MRI of local disease in nasopharyngeal carcinoma: tumour extent vs tumour stage. Br. J. Radiol. 72(860), 734-741.

King AD, Ma BB, Yau YY, Zee B, Leung SF, Wong JKT, Kam MKM, Ahuja T, \& Chan ATC (2008). The impact of 18 FDG PET/CT on assessment of nasopharyngeal carcinoma at diagnosis. The British Journal of Radiology. 81:291-298.

King AD, Teo P, Lam WW, Leung SF, Metreweli C (2000). Paranasopharyngeal space involvement in nasopharyngeal cancer: detection by CT and MRI. Clin. Oncol. (R. Coll. Radiol.) 12(6), 397-402.

King AD, Vlantis AC, Tsang RK et al. (2006). Magnetic resonance imaging for the detection of nasopharyngeal carcinoma. Am. J. Neuroradiol. 27(6), 1288-1291.

King AD, Tse GM, Ahuja AT et al (2004). Necrosis in metastatic neck nodes: diagnostic accuracy of CT, MR imaging, and US. Radiology. 230(3), 720-726.

Kumar MB, Lu JJ, Loh KS et al. (2004). Tailoring distant metastatic imaging for patients with clinically localized undifferentiated nasopharyngeal carcinoma. Int. J. Radiat. Oncol. Biol. Phys. 58(3), 688-693.

Lartigau E, Le Ridant AM, Lambin P, Weeger P, Martin L, Sigal R, Lusinchi A, Luboinski B,Eschwege F, Guichard M. (1993). Oxygenation of head and neck tumors. Cancer. 717:2319-2325.

Lau KY, Kan WK, Sze WM e tal (2004). Magnetic resonance for T-staging of nasopharyngeal carcinoma - the most informative pair of sequences. Jpn J. Clin. Oncol. 34(4), 171175.

Lee AW, Au JS, Teo PM et al. (Eds) (2004). Clin. Oncol. (R. Coll. Radiol.) 16(4), 269-276.

Lee AW, Poon YF, Foo W, Law SC, Cheung FK, Chan DK, Tung SY, Thaw M, Ho JH (1992). Retrospective analysis of 5037 patients with nasopharyngeal carcinoma treated 
during 1976-1985: overall survival and patterns of failure. Int J Radiat Oncol Biol Phys. 23(2):261.

Liang SB, Sun Y, Liu LZ et al. (2009). Extension of local disease in nasopharyngeal carcinoma detected by magnetic resonance imaging: improvement of clinical target volume delineation. Int. J. Radiat. Oncol. Biol. Phys. 75(3), 742-750.

Liao XB, Mao YP, Liu LZ, Tang LL, Sun Y, Wang Y, Lin AH, Cui CY, Li L, Ma J (2008). How does magnetic resonance imaging influence staging according to AJCC staging system for nasopharyngeal carcinoma compared with computed tomography? Int J Radiat Oncol Biol Phys. 72(5):1368-1377.

Lin XP, Zhao C, Chen MY, Fan W, Zhang X, Zhi SF, Liang PY (2008). Role of 18F-FDG $\mathrm{PET} / \mathrm{CT}$ in diagnosis and staging of nasopharyngeal carcinoma. Ai Zheng. 27(9):974-978.

Liu FY, Lin CY, Chang JT et al (2007). ${ }^{18}$ F-FDG PET can replace conventional work-up in primary $\mathrm{M}$ staging of nonkeratinizing nasopharyngeal carcinoma. J. Nucl. Med. 48(10), 1614-1619.

Liu MZ, Tang LL, Zong JF et al. (2008). Evaluation of sixth edition of AJCC staging system for nasopharyngeal carcinoma and proposed improvement. Int. J. Radiat. Oncol. Biol. Phys. 70(4), 1115-1123.

Liu T, Xu W, Yan WL, Ye M, Bai YR, Huang G (2007). FDG-PET, CT, MRI for diagnosis of local residual or recurrent nasopharyngeal carcinoma, which one is best? A systematic review. Radiotherapy and Oncology. 85:327-335.

Liu LZ, Zhang GY, Xie CM, Liu XW, Cui CY, Li L (2006). Magnetic resonance imaging of retropharyngeal lymph node metastasis in nasopharyngeal carcinoma: patterns of spread. Int J Radiat Oncol Biol Phys. 66: 721-730.

Lu JC, Wei Q, Zhang YQ, Li F (2004). Influence of MRI abnormality in skull base bone on prognosis of nasopharyngeal carcinoma. Cancer Radiother. 8: 230-233.

Mao YP, Liang SB, Liu LZ, Chen Y, Sun Y, Tang LL, Tian L, Lin AH, Liu MZ, Li L, Ma J (2008). The N staging system in nasopharyngeal carcinoma with radiation therapy oncology group guidelines for lymph node levels based on magnetic resonance imaging. Clin Cancer Res. 14: 7497-7503

Mao YP, Xie FY, Liu LZ et al (2009). Re-evaluation of 6th edition of AJCC staging system for nasopharyngeal carcinoma and proposed improvement based on magnetic resonance imaging. Int. J. Radiat. Oncol. Biol. Phys. 73(5), 1326-1334.

Ng S, Chan S, Yen T, Chang JT, Ko S, Wang H, Lin C, Chang K, Lin Y (2010). Comprehensive imaging of residual/recurrent nasopharyngeal carcinoma using whole-body MRI at 3 T compared with FDG-PET-CT. Eur Radiol. 20:2229-2240.

Ng S, Chan S, Yen T, Chang JT, Liao C, Ko S, Liu F, Chin S, Fan K, Hsu C (2009). Staging of untreated nasopharyngeal carcinoma with PET/CT: comparison with conventional imaging work-up. Eur J Nucl Med Mol Imaging. 36:12-22.

Ng SH, Chang JT, Chan SC, Ko SF, Wang HM, Liao CT, Chang YC, Yen TC (2004). Nodal metastases of nasopharyngeal carcinoma: patterns of disease on MRI and FDG PET. Eur J Nucl Med Mol Imaging. 31: 1073-1080.

$\mathrm{Ng} \mathrm{SH}$, Chang TC, Ko SF et al. (1997). Nasopharyngeal carcinoma: MRI and CT assessment. Neuroradiology. 39(10), 741-746. 
Olmi P, Fallai C, Colagrande S, Giannardi G (1995). Staging and follow-up of nasopharyngeal carcinoma: magnetic resonance imaging versus computerized tomography. Int. J. Radiat. Oncol. Biol. Phys. 32(3), 795-800.

Parkin DM, Bray F, Ferlay J, Pisani P (2005). Global cancer statistics. CA Cancer J Clin. 55:74108.

Parkin DM, Whelan SL, Ferlay J, Teppo L, Thomas DB, editors (2002). Cancer incidence in five continents, vol. VIII. IARC scientific publications No. 155. Lyon: IARC.

Ren EC \& Chan SH (1996). Human leucocyte antigens and nasopharyngeal carcinoma. Clin. Sci. (Lond.) 91(3), 256-258.

Roh JL, Sung MW, Kim KH, Choi BY, Oh SH, Rhee CS, Ha JW (2004). Nasopharyngeal carcinoma with skull base invasion: a necessity of staging subdivision. Am J Otolaryngol. 25(1):26-32.

Sakata K, Hareyama M, Tamakawa M, Oouchi A, Sido M, Nagakura H, Akiba H, Koito K, Himi T, \& Asakura K (1999). Prognostic factors of nasopharynx tumors investigated by MR imaging and the value of MR imaging in the newly published TNM staging. Int J Radiat Oncol Biol Phys. 43(2):273.

Som PM (1987). Lymph nodes of the neck. Radiology. 165:593-600.

Som PM, Brandwein MS. Lymph nodes. In: Som PM, Curtin HD,editors (2003). Head and Neck Imaging. 4th ed. Vol 2. Mosby Inc. 1910-1911.

Som PM, Curtin HD, Mancuso AA (1999). An imaging-based classification for the cervical nodes designed as an adjunct to recent clinically based nodal classifications. Arch Otolaryngol Head Neck Surg. 125:388-396.

Su Y, Zhao C, Xie CM, Lu LX, Sun Y, Han F, Wu HB, Cui NJ, Zeng ZY, Lu TX (2006). Evaluation of CT, MRI and PET/CT in detecting retropharyngeal lymph node metastasis in nasopharyngeal carcinoma. Ai Zheng. 25(5):521-525.

Sze WM, Lee AW, Yau TK, Yeung RM, Lau KY, Leung SK, Hung AW, Lee MC, Chappell R, Chan K. (2004) Primary tumor volume of nasopharyngeal carcinoma prognostic significance for local control. Int J Radiat Oncol Biol Phys. 59:21-27.

Teo PM, Kwan WH, Lee WY, Leung SF, Johnson PJ (1996). Prognosticators determining survival subsequent to distant metastasis from nasopharyngeal carcinoma. Cancer. 77(12), 2423-2431.

Teo P, Lee WY, Yu P (1996). The prognostic significance of parapharyngeal tumour involvement in nasopharyngeal carcinoma. Radiother. Oncol. 39(3), 209-221.

Wang XS, Hu CS, Ying HM, Zhou ZR, Ding JH, Feng Y (2009). Patterns of retropharyngeal node metastasis in nasopharyngeal carcinoma. Int J Radiat Oncol Biol Phys.73(1):194-201.

Wang GH, Lau EW, Shakher R, Binns DS, Hogg A, Drummond E, Hicks RJ (2007). Clinical application of (18)F-FDG PET/CT to staging and treatment effectiveness monitoring of nasopharyngeal carcinoma. Ai Zheng.26(6):638-42.

Wei WI \& Sham JST (2005). Nasopharyngeal carcinoma. Lancet. 365:2041-2054.

Yoshizaki T, Ito M, Murono S, Wakisaka N, Kondo S, \& Endo K (2011). Current understanding and management of nasopharyngeal carcinoma. Auris Nasus Larynx. Article in press. 
Yousem DM, Som PM, Hackney DB, Schwaibold F, Hendrix RA (1992). Central nodal necrosis and extracapsular spread in cervical lymph nodes: MR imaging versus CT. Radiology. 182:753-759.

Yu E, O'Sullivan B, Kim J, Siu L, Bartlett E (2010). Magnetic resonance imaging of nasopharyngeal carcinoma. Expert Rev. Anticancer Ther. 10(3): 365-375.

Yu MC, Mo CC, Chong WX et al. Preserved foods and nasopharyngeal carcinoma: a casecontrol study in Guangxi, China. Cancer Res. 48, 1954-1959 (1988).

Zhang GY, Hu WH, Liu LZ, Wu HB, Gao YH, Li L, Pan Y, Wang QS (2006). Comparison between PET/CT and MRI in diagnosing lymph node metastasis and $\mathrm{N}$ staging of nasopharyngeal carcinoma. Zhonghua Zhong Liu Za Zhi. 28(5):381-4. 


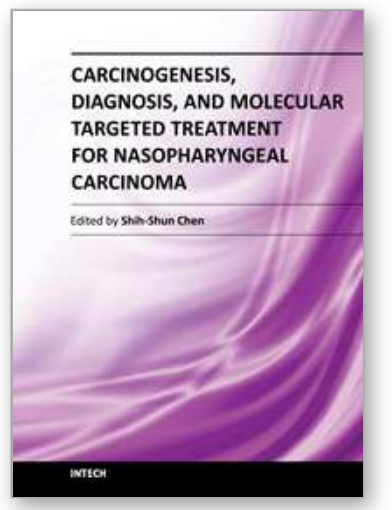

\section{Carcinogenesis, Diagnosis, and Molecular Targeted Treatment for Nasopharyngeal Carcinoma}

Edited by Dr. Shih-Shun Chen

ISBN 978-953-307-867-0

Hard cover, 246 pages

Publisher InTech

Published online 15, February, 2012

Published in print edition February, 2012

This book is a comprehensive treatise of the potential risk factors associated with NPC development, the tools employed in the diagnosis and detection of NPC, the concepts behind NPC patients who develop neuroendocrine abnormalities and ear-related complications after radiotherapy and chemotherapy, the molecular mechanisms leading to NPC carcinogenesis, and the potential therapeutic molecular targets for NPC.

\section{How to reference}

In order to correctly reference this scholarly work, feel free to copy and paste the following:

Michael Chan, Eric Bartlett, Arjun Sahgal, Stephen Chan and Eugene Yu (2012). Imaging of Nasopharyngeal Carcinoma, Carcinogenesis, Diagnosis, and Molecular Targeted Treatment for Nasopharyngeal Carcinoma, Dr. Shih-Shun Chen (Ed.), ISBN: 978-953-307-867-0, InTech, Available from:

http://www.intechopen.com/books/carcinogenesis-diagnosis-and-molecular-targeted-treatment-fornasopharyngeal-carcinoma/imaging-of-nasopharyngeal-carcinoma

\section{INTECH}

open science | open minds

\author{
InTech Europe \\ University Campus STeP Ri \\ Slavka Krautzeka 83/A \\ 51000 Rijeka, Croatia \\ Phone: +385 (51) 770447 \\ Fax: +385 (51) 686166 \\ www.intechopen.com
}

\author{
InTech China \\ Unit 405, Office Block, Hotel Equatorial Shanghai \\ No.65, Yan An Road (West), Shanghai, 200040, China \\ 中国上海市延安西路65号上海国际贵都大饭店办公楼 405 单元 \\ Phone: +86-21-62489820 \\ Fax: $+86-21-62489821$
}


(C) 2012 The Author(s). Licensee IntechOpen. This is an open access article distributed under the terms of the Creative Commons Attribution 3.0 License, which permits unrestricted use, distribution, and reproduction in any medium, provided the original work is properly cited. 